\title{
Comparison of quality of life and depression between hematopoietic stem cell transplantation survivors and their spouse caregivers
}

\author{
Silvia Park ${ }^{1,2}$, Eun-kyung Choi ${ }^{4}$, Im-Ryung Kim ${ }^{4}$, Juhee Cho ${ }^{4,5,6}$, Jun Ho Jang ${ }^{3}$ \\ ${ }^{1}$ Department of Hematology, Catholic Hematology Hospital, Seoul St. Mary's Hospital, ${ }^{2}$ Leukemia Research Institute, College of \\ Medicine, The Catholic University of Korea, ${ }^{3}$ Division of Hematology-Oncology, Department of Medicine, ${ }^{4}$ Cancer Education \\ Center, Samsung Medical Center, Sungkyunkwan University School of Medicine, ${ }^{5}$ Department of Clinical Research Design and \\ Evaluation, SAIHST, Sungkyunkwan University, Seoul, Korea, ${ }^{6}$ Department of Health, Behavior and Society, Johns Hopkins \\ Bloomberg School of Public Health, Baltimore, MD, USA
}

p-ISSN 2287-979X / e-ISSN 2288-0011 https://doi.org/10.5045/br.2019.54.2.137 Blood Res 2019;54:137-143.

Received on October 30, 2018

Revised on March 30, 2019

Accepted on April 1, 2019

\section{Background}

Hematopoietic stem cell transplantation (HSCT) is an exhausting process that impacts both the patient and caregiver.

\section{Methods}

This was a cross-sectional, HSCT survivor-spouse caregiver matching study to determine quality of life (QoL) and depression among HSCT survivors and their caregivers. QoL and depression were measured with the World Health Organization Quality of Life: Brief Version (26 items) and the 9-item Patient Health Questionnaire, respectively. Data from 97 married couples were analyzed.

\section{Results}

There were no significant differences in overall QoL and psychological, social, and environmental health between survivors and spouse caregivers $(P=0.345,0.424,0.415$, and $0.253)$; however, physical QoL was better in the spouse caregiver group $(P=0.011)$. There was no difference in mean depression scale scores (5.3 vs. 5.1, $P=0.812$ ) or proportion of severe depression $(15.6 \%$ vs. $13.7 \%, P=0.270)$ between the two groups. We found that family income had a significant impact on overall QoL and environmental health among spouse caregivers $(P=0.013$ and 0.023$)$, and female gender, co-morbidities, and family income were the important factors associated with depression among spouse caregivers $(P=0.007,0.017$ and 0.049$)$.

\section{Conclusion}

This study found that there were no significant differences in QoL or level of depression between HSCT survivors and their spouse caregivers. Family income, gender, and co-morbidities showed significant association with spouse caregiver distress.

Key Words Hematopoietic stem cell transplantation, Survivor, Caregiver, Quality of life, Depression

\section{INTRODUCTION}

Hematopoietic stem cell transplantation (HSCT) offers a chance of cure to patients with fatal hematologic diseases $[1,2]$. Over the past few decades, there have been remarkable advances in transplantation techniques and supportive care strategies, which directly translates into a significant improvement in survival after HSCT [3-5]. Seventy to eighty percent of survivors at first 2 years after HSCT are believed to become long-term survivors [3-5]. Due to the increasing survival rates for HSCT recipients, long-term health conditions and quality of life (QoL) among this population have been gaining more attention, and several studies have addressed these issues [6, 7]. However, far less studies have investigated QoL among caregivers of HSCT survivors.

Due to the nature of the hematologic malignancy or bone marrow failure syndrome, which can be potentially cured after treatment, patients are more likely to be exposed to intensive protocols that yield significant toxicities during 
the treatment period. The disease itself is also commonly associated with dangerous medical conditions such as pancytopenia and severe infection. Therefore, patients with hematologic diseases who are being actively treated often require close monitoring and management by their primary caregivers $[8,9]$. Thus, it can be expected that these caregivers experience high levels of mental distress and physical strain [10]. One previous Japanese study demonstrated that mothers of children with leukemia requiring hospital care have poor health-related QoL and were at a greater risk for deteriorated mental health, social functioning, and depression [11].

The focus of this study was on spouse caregivers of HSCT survivors. Hematopoietic stem cell transplantation is an exhausting process. Patients typically undergo multiple rounds of chemotherapy before HSCT for disease control. Although HSCT is often used as the final step of a treatment strategy for the cure, the results are not always satisfactory. Sometimes, though they achieve a cure, patients may suffer from chronic complications for several years after HSCT [12]. During this whole process, the caregiver is often the sole provider of physical and psychological support for the patients, and has to bear the burden of caring for these fragile patients for a long time. These details suggest that caregivers inevitably suffer from exhaustion and that not only HSCT survivors but their caregivers may be vulnerable physically or psychologically. Thus, we conducted a cross-sectional, HSCT survivor-spouse caregiver matching study to assess QoL and depression among the spouse caregivers.

\section{MATERIALS AND METHODS}

\section{Subjects and purpose of the study}

The present study was part of a wider cross-sectional study investigating the dyadic concordance of sexuality among HSCT patients and their partners [13]. For the present study, HSCT survivors and their partners were recruited through the post-HSCT registry from Samsung Medical Center and the Korea Blood Cancer Association. The inclusion criteria were as follows: female or male subjects aged at least 20 years, had undergone autologous or allogenic HSCT, had an Eastern Cooperative Oncology Group performance status of 0 to 2 , was able to communicate well with the investigators and to understand and fill out the questionnaire, and provided written informed consent prior to study enrollment. Patients presenting with any of the following were not eligible to participate in the study: had no sexual partner, had undergone autologous HSCT in the past 3 months and allogenic HSCT in the past 6 months, and was medically incapable of sexual activity (e.g., past history of genitourinary surgery). Partners of the included subjects were also recruited in the study. For the present study, some adjustments were made to the inclusion criteria of the original study. The original study included patients who had undergone autologous HSCT in the past 3 months and allogenic HSCT in the past 6 months and excluded patient-partner pairs who were not married. From September 2013 to March 2015, a total of 106 HSCT patient-partner pairs were administered a set of questionnaires for the assessment of sexual activity, QoL, depression, fear of recurrence, body image, and caregiver burden. This study was approved by the institutional review boards of Samsung Medical Center. All procedures were carried out in accordance with the Declaration of Helsinki.

The present study focused on the analysis of QoL and depression among spouse caretakers of HSCT survivors. The co-primary end points were i) differences in QoL and depression between caregiver spouses and HSCT survivors and ii) factors associated with QoL and depression among caregiver spouses. Among a total of 106 HSCT patient-partner pairs, the data from 97 married couples were used in the analysis (Fig. 1).

\section{Data collection and study measures}

The questionnaires for the patients and spouse caregivers were identical, and each consisted of six parts. Each part of the questionnaires contained items on sexual activity, QoL, depression, fear of recurrence, body image, and caregiver burden. Among these items, QoL and depression were of primary interest in this analysis, and assessment measures for each were as follows:

Quality of life: The World Health Organization Quality of Life: Brief Version (26 items) (WHOQOL-BREF 26) was used to assess QoL. The WHOQOL-BREF 26 measures 4 QoL domains: physical health (7 items), psychological health (6 items), social relationships (3 items), and environmental health (8 items). The WHOQOL-BREF 26 also contains QoL and general health items. The mean score of items within

$\begin{aligned} & \text { Between September } 2013 \text { and March 2015, patients who received hematopoietic stem cell } \\ & \text { transplantation for hematologic malignancies and had no evidence of recurrent disease } \\ & (\mathrm{N}=175)\end{aligned}$
\[ \begin{array}{l}\text { Exclusions }(\mathrm{N}=78) \\ \text { Without a partner }(\mathrm{N}=69) \\ \text { Incomplete information }(\mathrm{N}=7) \\ \text { Paired answer, but not married }(\mathrm{N}=2)\end{array} \]
$\begin{gathered}\text { Hematopoietic stem cell transplantation survivors and their spouses paired in the final analysis } \\ (\mathrm{N}=97)\end{gathered}$

Fig. 1. Flow diagram of subject enrollment. 
each domain is used to calculate the domain score, and raw scores are transformed to scores ranging from 4 to 20. Higher scores denote better QoL.

Depression: The 9-item Patient Health Questionnaire (PHQ9) was used for screening and measuring the severity of depression. It contains the following 9 items: loss of interest, feeling depressed, sleep problems, loss of energy, appetite problems, self-blame, concentration problems, agitation/retardation, and suicidal ideation. The sum score (range, 0 to 27) indicates the degree of depression, and a score $\geq 10$ indicates severe depression.

\section{Statistical analyses}

We used descriptive statistics to examine the distribution of characteristics among HSCT survivors and their spouse caregiver. Comparison of the differences in QoL and depression between HSCT patients and spouse caregivers were analyzed using paired $t$-test. Difference in the proportion of severe depression between the 2 groups was examined using the $\chi^{2}$ test. To determine the factors associated with QoL and depression among spouse caregivers, we performed a multivariate linear regression with both "patients factor" and "caregivers factor" in the model. In regression results, if the correlation coefficient is negative, it provides statistical evidence of a negative relationship between the variables. In the multivariate analysis, we adjusted for variables that could be potential confounders: age, gender, employment status, income, co-morbidity, disease at diagnosis, type of transplantation, and chronic graft versus host disease. All statistical analysis were performed using STATA software (version 12.0; STATA Corp., Houston, TX, USA). Statistical significance was set at $P<0.05$.

\section{RESULTS}

\section{Characteristics of hematopoietic stem cell transplantation} survivors and their spouse caregivers

Table 1 shows the characteristics of the HSCT survivors and their spouse caregivers. The mean age of the spouse caregivers was slightly lower than that of the HSCT survivors [49.7 yr (range, 30-73) and $51.6 \mathrm{yr}$ (range, 30-72), respectively]. There were more female caregivers $(\mathrm{N}=65,67 \%)$ for male patients than male caregivers $(\mathrm{N}=32,33.0 \%)$ for female patients. All caregivers described here were patients' spouses.

Approximately half of the caregivers were either employed $(\mathrm{N}=22,22.7 \%)$ or self-employed $(\mathrm{N}=24,24.7 \%)$. Among the HSCT survivors, leave of absence $(\mathrm{N}=20,20.6 \%)$ and unemployment status $(\mathrm{N}=20,20.6 \%)$ were the most common classification regarding employment, which was followed by being in paid employment $(\mathrm{N}=16,16.5 \%)$, retirement $(\mathrm{N}=12,12.4 \%)$, and running their own business $(\mathrm{N}=10$, $10.3 \%)$. When assuming that $\$ 2,000-4,000$ is the average monthly income in South Korea, more than $70 \%$ of HSCT survivors and spouse caregivers responded that they earned an average or above-average income.
Co-morbidity was defined as the presence of cerebrovascular or cardiovascular disease; diabetes mellitus; hypertension; or pulmonary, hepatic, gastrointestinal, renal, musculoskeletal, gynecological, or ophthalmic disorder.

Table 1. Characteristics of participants.

\begin{tabular}{|c|c|c|}
\hline \multirow{2}{*}{ Characteristics } & \multicolumn{2}{|c|}{ Survivor-spouse caregiver pair } \\
\hline & $\begin{array}{l}\text { Survivor, } \\
N=97(\%)\end{array}$ & $\begin{array}{c}\text { Spouse caregiver, } \\
\quad \mathrm{N}=97(\%)\end{array}$ \\
\hline Age (yr), mean (SD) & $51.6(9.4)$ & $49.7(9.9)$ \\
\hline \multicolumn{3}{|l|}{ Gender } \\
\hline Male & $65(67.0)$ & $32(33.0)$ \\
\hline Female & $32(33.0)$ & $65(67.0)$ \\
\hline Marital status, married & $97(100.0)$ & $97(100.0)$ \\
\hline \multicolumn{3}{|l|}{ Education } \\
\hline High school graduate & $44(48.9)$ & $45(46.4)$ \\
\hline More than college & $46(51.1)$ & $52(53.6)$ \\
\hline \multicolumn{3}{|l|}{ Employment status } \\
\hline Employed & $16(16.5)$ & $22(22.7)$ \\
\hline Self-employed & $10(10.3)$ & $24(24.7)$ \\
\hline Leave of absence & $20(20.6)$ & $6(6.2)$ \\
\hline Retired & $12(12.4)$ & $4(4.1)$ \\
\hline Housewife & $15(15.5)$ & $29(29.9)$ \\
\hline Student & $1(1.0)$ & $1(1.0)$ \\
\hline Unemployed & $20(20.6)$ & $5(5.2)$ \\
\hline Etc. & $3(3.1)$ & $6(6.2)$ \\
\hline \multicolumn{3}{|l|}{ Family income (\$) } \\
\hline$<\$ 2,000$ & $29(29.9)$ & $27(28.1)$ \\
\hline$\$ 2,000-\$ 4,000$ & $35(36.1)$ & $36(37.5)$ \\
\hline$>\$ 4,000$ & $33(34.0)$ & $33(34.4)$ \\
\hline Co-morbidity (yes) & $40(41.2)$ & $53(55.2)$ \\
\hline Taking any medication (yes) & $51(54.8)$ & $24(25.3)$ \\
\hline $\begin{array}{l}\text { Taking psychiatric } \\
\text { medication other than } \\
\text { sleeping pills (yes) }\end{array}$ & $7(7.2)$ & $5(5.2)$ \\
\hline \multicolumn{3}{|c|}{ Below items were only for patients } \\
\hline $\begin{array}{l}\text { Time since diagnosis }(y r), \\
\text { mean }(\mathrm{SD}) / \text { range }\end{array}$ & $\begin{array}{r}4.3(4.6) / \\
0.6-26.7\end{array}$ & \\
\hline $\begin{array}{l}\text { Time since transplant (yr), } \\
\text { mean (SD)/range }\end{array}$ & $\begin{array}{r}3.2(3.6) / \\
0.2-15.7\end{array}$ & \\
\hline \multicolumn{3}{|l|}{ Disease at diagnosis } \\
\hline $\mathrm{AML}$ & $36(38.3)$ & \\
\hline ALL & $8(8.5)$ & \\
\hline Lymphoma & $10(10.6)$ & \\
\hline Myeloma & $24(25.5)$ & \\
\hline MDS & $9(9.6)$ & \\
\hline SAA & $6(6.4)$ & \\
\hline Etc. & $1(1.1)$ & \\
\hline $\begin{array}{l}\text { Age at the time of HSCT } \\
(\mathrm{yr}) \text {, mean }(\mathrm{SD}) / \text { range }\end{array}$ & $\begin{array}{c}47(9.5) / \\
26-69\end{array}$ & \\
\hline \multicolumn{3}{|l|}{ Type of transplant } \\
\hline Autotransplant & $30(31.3)$ & \\
\hline Allotransplant & $67(68.7)$ & \\
\hline Acute GVHD (yes) & $26(26.8)$ & \\
\hline Chronic GVHD (yes) & $51(52.6)$ & \\
\hline Immune medication (yes) & $33(35.1)$ & \\
\hline
\end{tabular}

Abbreviations: GVHD, chronic graft versus host disease; HSCT, hematopoietic stem cell transplantation. 
More than half of the spouse caregivers $(\mathrm{N}=53,55.2 \%)$ reported that they had co-morbidities, whereas less than half of the HSCT survivors ( $\mathrm{N}=40,41.2 \%)$ manifested these problems. More HSCT survivors ( $\mathrm{N}=51,54.8 \%)$ than spouse caregivers $(\mathrm{N}=24,25.3 \%)$ were taking medication at the time of survey. The numbers of HSCT survivors and spouse caregivers on psychiatric medication other than sleeping pills were 7 and 5 (7.2\% and 5.2\%), respectively.

\section{Hematopoietic stem cell transplantation survivors' clinical characteristics}

Among patients, mean duration since diagnosis was 4.3 years at the time of survey, ranging from 0.6 to 26.7 years, and acute myeloid leukemia was the most common reason for undergoing HSCT ( $\mathrm{N}=36,38.3 \%)$ (Table 1). There were more patients who had undergone allogeneic HSCT $(\mathrm{N}=67$, $68.7 \%)$ than patients who had undergone autologous HSCT $(\mathrm{N}=30,31.3 \%)$ in this study. At the time of survey, 33 patients (35.1\%) were taking immune suppressive agent, and the numbers of patients who responded that they experienced acute and chronic graft versus host disease was 26 (26.8\%) and 51 (52.6\%), respectively.

Assessment of quality of life and depression: comparison between hematopoietic stem cell transplantation survivors and caregivers

Table 2 shows the results of the comparison of QoL and depression between HSCT survivors and their spouse caregivers. In our comparison of QoL between the two groups, we found that there were no significant differences in overall $\mathrm{QoL}$ and general health. Among the $4 \mathrm{QoL}$ domains, psychological, social, and environmental health showed no significant differences between HSCT survivors and their spouse caregivers. Whereas physical health was found to be better in spouse caregivers compared with HSCT survivors (14.2 vs. $13.1 ; P=0.011$ ). With regard to depression, HSCT survivors suffered slightly more from depression than spouse caregivers (5.3 vs. 5.1 for the mean scale; $15.6 \%$ vs. $13.7 \%$ for the proportion of severe depression), but the difference was not statistically significant.

\section{Factors associated with quality of life and depression among} spouse caregivers

The results of the multivariate analysis of factors associated with QoL and depression among spouse caregivers are shown in Table 3. After adjusting for both HSCT survivor and spouse caregiver factors, we found that spouse caregivers of survivors who had higher monthly family incomes $(>\$ 4,000)$ were more likely to have better overall QoL and environmental health [by 3.24 (standard error, $\mathrm{SE}=1.27$ ) and 2.24 (SE=1.27) points] compared with spouse caregivers of survivors who had lower monthly family incomes $(<\$ 4,000)$. This finding was statistically significant $(P<0.05)$. With regard to depression, spouse caregivers who were caring for female survivors were less likely to have depression [by 8.22 ( $\mathrm{SE}=3.69)$ points] compared with spouse caregivers who were caring for male survivors $(P<0.05)$. Spouse caregivers of survivors who had higher monthly family incomes $(>\$ 4,000)$ were less likely to have depression [by 2.78 ( $\mathrm{SE}=1.38)$ points] compared with spouse caregivers of survivors who had lower monthly family incomes $(<\$ 4,000)$. This finding was statistically significant $(P<0.05)$. Gender was among the spouse caregiver factors associated with higher rates of depression [females, by 10.24 (SE=3.67) points, compared with males]. This finding was statistically significant $(P<0.05)$. Spouse caregivers without comorbid conditions were less likely to have depression [by 2.58 (SE=1.06) points] compared with spouse caregivers with comorbid conditions $(P<0.05)$.

\section{DISCUSSION}

In this study of 97 HSCT survivor and spouse caregiver pairs, we identified that caregiver QoL was generally com-

Table 2. Comparison of quality of life and depression between HSCT survivors and their spouse caregivers.

\begin{tabular}{|c|c|c|c|}
\hline & \multicolumn{3}{|c|}{ Survivor-spouse caregiver pair $(\mathrm{N}=97)$} \\
\hline & Patient, mean (SD) & Caregiver, mean (SD) & $P$ \\
\hline \multicolumn{4}{|l|}{ Quality of life ${ }^{\text {a) }}$} \\
\hline Overall quality of life and general health & $11.3(4.4)$ & $11.8(3.8)$ & 0.345 \\
\hline Physical health & $13.1(3.7)$ & $14.2(3.0)$ & 0.011 \\
\hline Psychological & $13.3(3.4)$ & $13.0(3.1)$ & 0.424 \\
\hline Social relationships & $11.7(3.8)$ & $12.1(3.6)$ & 0.415 \\
\hline Environment & $12.5(3.2)$ & $12.1(2.8)$ & 0.253 \\
\hline \multicolumn{4}{|l|}{ Depression $^{\text {b) }}$} \\
\hline Mean (SD) & $5.3(4.5)$ & $5.1(4.8)$ & 0.812 \\
\hline \multicolumn{4}{|l|}{ Severity of depression $(\mathrm{N}, \%)$} \\
\hline Normal $(0-9)$ & $81(84.4)$ & $82(86.3)$ & 0.270 \\
\hline Abnormal (10-27) & $15(15.6)$ & $13(13.7)$ & \\
\hline
\end{tabular}




\begin{tabular}{|c|c|c|c|c|c|c|}
\hline \multirow{2}{*}{ Characteristics } & \multicolumn{5}{|c|}{ WHOQOL-BREF 26} & \multirow{2}{*}{$\begin{array}{l}\text { Depression } \\
\text { coef. (SE) }\end{array}$} \\
\hline & $\begin{array}{l}\text { Overall health } \\
\text { coef. (SE) }\end{array}$ & $\begin{array}{l}\text { Physical } \\
\text { coef. (SE) }\end{array}$ & $\begin{array}{l}\text { Psychological } \\
\text { coef. (SE) }\end{array}$ & $\begin{array}{c}\text { Social } \\
\text { coef. (SE) }\end{array}$ & $\begin{array}{l}\text { Environmental } \\
\text { coef. (SE) }\end{array}$ & \\
\hline \multicolumn{7}{|l|}{ HSCT survivor factor } \\
\hline Age & $-0.03(0.13)$ & $0.11(0.12)$ & $0.07(0.11)$ & $0.04(0.14)$ & $0.01(0.10)$ & $0.26(0.16)$ \\
\hline \multicolumn{7}{|l|}{ Gender (ref. male) } \\
\hline Female & $0.81(2.87)$ & $-2.70(2.49)$ & $-1.20(2.43)$ & $1.01(3.05)$ & $0.62(2.25)$ & $-8.22(3.69)^{\mathrm{e})}$ \\
\hline \multicolumn{7}{|c|}{ Employment status (ref. employed) } \\
\hline Unemployed & $1.18(1.03)$ & $0.44(0.90)$ & $1.55(0.89)$ & $-0.22(1.14)$ & $0.19(0.82)$ & $0.50(1.20)$ \\
\hline \multicolumn{7}{|l|}{ Income (\$) (ref. $\$ 2,000)$} \\
\hline $2,000-4,000$ & $2.25(1.24)$ & $1.13(1.04)$ & $0.54(1.01)$ & $1.55(1.27)$ & $0.77(0.94)$ & $-0.96(1.27)$ \\
\hline $4,000+$ & $3.24(1.27)^{\mathrm{c})}$ & $1.27(1.04)$ & $0.64(1.05)$ & $1.75(1.32)$ & $2.24(0.96)^{d)}$ & $-2.78(1.38)^{f)}$ \\
\hline \multicolumn{7}{|l|}{ Co-morbidity (ref. yes) } \\
\hline No & $1.16(0.97)$ & $-0.37(0.78)$ & $0.59(0.81)$ & $-0.24(1.00)$ & $0.08(0.73)$ & $0.82(1.08)$ \\
\hline \multicolumn{7}{|c|}{ Disease at diagnosis (ref. etc.) } \\
\hline $\mathrm{AML}$ & $1.38(0.95)$ & $0.21(0.81)$ & $0.38(0.81)$ & $0.50(1.04)$ & $-0.15(0.75)$ & $-0.91(1.23)$ \\
\hline \multicolumn{7}{|c|}{ Type of transplantation (ref. Auto) } \\
\hline Allo & $-0.26(1.55)$ & $0.34(1.30)$ & $-0.05(1.32)$ & $1.37(1.65)$ & $2.40(1.21)$ & $-0.75(1.65)$ \\
\hline \multicolumn{7}{|l|}{ Chronic GVHD (ref. no) } \\
\hline Yes & $-1.08(1.21)$ & $-1.20(1.04)$ & $-0.54(1.04)$ & $-1.63(1.29)$ & $-1.02(0.96)$ & $2.21(1.52)$ \\
\hline \multicolumn{7}{|l|}{ Spouse caregiver factor } \\
\hline Age & $0.10(0.13)$ & $-0.07(0.12)$ & $-0.03(0.11)$ & $-0.01(0.13)$ & $0.01(0.10)$ & $-0.20(0.14)$ \\
\hline \multicolumn{7}{|l|}{ Gender (ref. male) } \\
\hline Female & $-2.21(2.87)$ & $0.66(2.45)$ & $-1.18(2.45)$ & $-1.52(3.07)$ & $-1.99(2.27)$ & $10.24(3.67)^{\mathrm{g})}$ \\
\hline \multicolumn{7}{|c|}{ Employment status (ref. employed) } \\
\hline Unemployed & $0.28(0.93)$ & $1.06(0.81)$ & $1.32(0.84)$ & $1.23(1.01)$ & $-0.39(0.74)$ & $1.68(1.12)$ \\
\hline \multicolumn{7}{|l|}{ Co-morbidity (ref. yes) } \\
\hline No & $1.66(0.92)$ & $1.42(0.80)$ & $1.11(0.81)$ & $1.29(1.02)$ & $0.31(0.73)$ & $-2.58(1.06)^{\mathrm{h})}$ \\
\hline
\end{tabular}

${ }^{\text {a) }}$ For coefficients, a negative value indicates a negative relationship between the variables. ${ }^{\text {b) }} P<0.05 .{ }^{\mathrm{c})} P=0.013 .{ }^{\mathrm{d})} P=0.023 .{ }^{\mathrm{e})} P=0.032$. ${ }^{\text {f) }} P=0.049 .{ }^{\text {g) }} P=0.007 .{ }^{\text {h) }} P=0.017$.

Abbreviations: coef., coefficient; GVHD, chronic graft versus host disease; $\mathrm{HSCT}$, hematopoietic stem cell transplantation; ref., reference; SE, standard error; WHOQOL-BREF 26, World Health Organization Quality of Life: Brief Version (26 items).

parable to, but not better than that of HSCT survivors. There was also no difference between HSCT survivors and spouse caregivers with respect to the level of depression or the proportion of participants whose depression was considered to be severe. In addition, it was observed that several physical and psychosocial factors were associated with QoL and depression among spouse caregivers. Family income was an important factor affecting distress among caregivers, and caregivers with higher family income exhibited better overall QoL, and were less depressed. Among spouse caregivers, being female and having co-morbidities was significantly linked to depression.

Not surprisingly, this was not the first study to investigate the psychosocial health of HSCT survivors and their caregivers, and various measures have been used to assess distress among this population [14-18]. Our study used the WHOQOL-BREF 26 [19-21] to assess QoL and the PHQ9 [22-25] to assess depression. Both measures have been widely used to investigate other medical conditions [26-29]; however, they have scarcely been introduced in HSCT conditions. Though the tools used in previous studies varied considerably, the results analyzed from previous studies and those observed in the present study were substantially consistent with regard to comparable QoL and depression between caregivers and HSCT survivors, and negative impact of female gender and health problems on caregiver outcome $[14,18]$. Although family income, as a great contributor to the QoL and depression of partners, has rarely been addressed before, the importance of social support was suggested based on a finding that poor social support negatively affects the QoL and post traumatic growth of partners [18].

It is also worthy to note that the caregivers frequently experienced physical health problems [30]. Although physical health-related QoL was reported to be better in spouse caregivers when they were compared with HSCT survivors, more than half of partners $(55.2 \%)$ in this study responded that they had one or more co-morbidities at the time of survey. This percentage was surprisingly high considering that the percentage of HSCT survivors who reported that they had co-morbidities was $41.2 \%$. Because the questionnaire for the assessment of co-morbid conditions consists of a broad range of items that are ambiguous and potentially permit subjective interpretation, it is highly likely that many subjective symptoms were considered co-morbidities in this 
study. For example, when evaluating the presence of digestive diseases, mild "dyspepsia" could be answered as either "yes" or "no," by the subject, depending on his or her perspective. This ambiguity was also present in items on musculoskeletal disorders; myalgia or arthralgia could be arbitrarily regarded as having or not having a musculoskeletal disorder by individual responders. Given that emotional distress and burnout may manifest as nonspecific symptoms, the high percentage of spouse caregivers reporting that they had co-morbidities may indicate not only physical but mental health concerns. In fact, the psychological, social, and environmental health problems and depression observed in spouse caregivers were almost equal to that assessed in HSCT survivors.

Particularly, we noticed that the percentage of HSCT survivors and spouse caregivers exhibiting abnormal depression levels was considerably high, which were $15.6 \%$ and $13.7 \%$, respectively $(P=0.270)$. According to the 2014 Korea National Health \& Nutrition Examination Survey, $6.6 \%$ of the general population has significant depression defined by a PHQ9 score of 10 or higher. Although the spouse caregiver is not the person who undergoes chemotherapy or HSCT and may be considered to be of normal health, he or she suffers from more depression than the general population. This finding has also been well-demonstrated in a previous study [18], where survivor acquaintances were enrolled as matched controls. In that study, survivors and partners reported more depressive symptoms than controls $(P<0.001)$, and risk of depression for partners was nearly 3.5 times that of controls $(P<0.002)$. Importantly, despite a substantial rate of depression, only 7 patients $(7.2 \%)$ and 5 caregivers $(5.2 \%)$ responded that they were taking psychiatric medication in the present study. Taken together, these findings suggest that there are unmet needs for psychosocial interventions in HSCT survivors as well as in their spouse caregivers; however, there have been no data on the effectiveness of interventions in these populations [31].

In this study, it was remarkable that family income highly impacted both caregiver QoL and depressive symptoms. To the best of our acknowledge, income as a contributing factor in psychosocial health, has not been previously analyzed. However, it can be assumed that the family of a patient who undergoes HSCT experiences significant loss of income due to medical expense during an entire course of treatment. This study found that only $26.8 \%$ of HSCT survivors earned an income, whereas approximately half of caregivers earned an income through paid employment or self-employment. Considering the composition of gender in each patient and caregiver group, where the dominance of male and female was shown per each, and that the economically active population in South Korea is mostly male, it is highly likely that the main income earner before the diagnosis was the HSCT survivor in the majority of families and that this role shifted to the partner over time. Our findings suggest that HSCT may affect the patient's ability to work and that difficulties on return to work related to social factors such as employment discrimination, should also be considered.
Although spouses are able to work, they are often exhausted from caring for the HSCT survivors; it has also been found that the transplant process also affects the caregiver's ability to work, which leads to a significant loss of income [32]. Income is an important factor in determining psychosocial health. Many factors inevitably contribute to the decrease or loss of income in the family of HSCT survivors. Factors in society that interrupt return to work among HSCT survivors, should be identified and addressed, and social and financial support is needed for the families at risk.

This study had several limitations. One of the major weaknesses was the absence of a control group to confirm the higher level of distress in caregiver participants compared with the general healthy population. Although we could find QoL reports that used the WHOQOL-BREF 26 and examined the general population [33, 34] (in which overall QoL as well as all sub-domains of QoL were much better in the general population than in the caregivers of our study), the comparison was limited by different nationality and research period; QoL differs from country to country and can change over time. In addition, we only considered spouse caregivers in this analysis although spouses cannot be the representatives of all caregivers. Because caregiving may also be provided by other family members, such as parents or children of a patient, relatives, or paid caregivers, interpretation of the result of this study should be limited to spouse caregivers.

In conclusion, the present study identified that there was no significant difference in $\mathrm{QoL}$ and the level of depression between HSCT survivors and spouse caregivers. In addition, gender, co-morbidities, and family income were the important factors associated with caregiver QoL and depression. We suggest that clinical psychosocial interventions that target both survivors and caregivers is needed, and that social support to families who are financially challenged has to be considered.

\section{ACKNOWLEDGMENTS}

The authors would like to thank the Korea Blood Cancer Association and the HSCT survivors and their spouses for their efforts in supporting this study.

\section{Authors' Disclosures of Potential Conflicts of Interest}

No potential conflicts of interest relevant to this article were reported.

\section{REFERENCES.}

1. Gupta V, Tallman MS, Weisdorf DJ. Allogeneic hematopoietic cell transplantation for adults with acute myeloid leukemia: myths, controversies, and unknowns. Blood 2011;117:2307-18.

2. Lim Z, Brand R, Martino R, et al. Allogeneic hematopoietic stem-cell transplantation for patients 50 years or older with 
myelodysplastic syndromes or secondary acute myeloid leukemia. J Clin Oncol 2010;28:405-11.

3. Bhatia S, Robison LL, Francisco L, et al. Late mortality in survivors of autologous hematopoietic-cell transplantation: report from the Bone Marrow Transplant Survivor Study. Blood 2005;105: 4215-22.

4. Socie G, Stone JV, Wingard JR, et al. Long-term survival and late deaths after allogeneic bone marrow transplantation. Late Effects Working Committee of the International Bone Marrow Transplant Registry. N Engl J Med 1999;341:14-21.

5. Bhatia S, Francisco L, Carter A, et al. Late mortality after allogeneic hematopoietic cell transplantation and functional status of long-term survivors: report from the Bone Marrow Transplant Survivor Study. Blood 2007;110:3784-92.

6. Sarkar S, Scherwath A, Schirmer L, et al. Fear of recurrence and its impact on quality of life in patients with hematological cancers in the course of allogeneic hematopoietic SCT. Bone Marrow Transplant 2014;49:1217-22.

7. Pidala J, Anasetti C, Jim H. Quality of life after allogeneic hematopoietic cell transplantation. Blood 2009;114:7-19.

8. Savoie ML, Nevil TJ, Song KW, et al. Shifting to outpatient management of acute myeloid leukemia: a prospective experience. Ann Oncol 2006;17:763-8.

9. Tamayo GJ, Broxson A, Munsell M, Cohen MZ. Caring for the caregiver. Oncol Nurs Forum 2010;37:E50-7.

10. McGrath P. Identifying support issues of parents of children with leukemia. Cancer Pract 2001;9:198-205.

11. Yamazaki S, Sokejima S, Mizoue T, Eboshida A, Fukuhara S. Health-related quality of life of mothers of children with leukemia in Japan. Qual Life Res 2005;14:1079-85.

12. Bhatia S. Long-term health impacts of hematopoietic stem cell transplantation inform recommendations for follow-up. Expert Rev Hematol 2011;4:437-52.

13. Yoo KH, Kang D, Kim IR, et al. Satisfaction with sexual activity and sexual dysfunction in hematopoietic stem cell transplantation survivors and their partners: a couple study. Bone Marrow Transplant 2018;53:967-76.

14. Beattie S, Lebel S. The experience of caregivers of hematological cancer patients undergoing a hematopoietic stem cell transplant: a comprehensive literature review. Psychooncology 2011;20: 1137-50.

15. Fife BL, Monahan PO, Abonour R, Wood LL, Stump TE. Adaptation of family caregivers during the acute phase of adult BMT. Bone Marrow Transplant 2009;43:959-66.

16. Bevans M, Wehrlen L, Prachenko O, Soeken K, Zabora J, Wallen GR. Distress screening in allogeneic hematopoietic stem cell (HSCT) caregivers and patients. Psychooncology 2011;20:615-22.

17. Foxall MJ, Gaston-Johansson F. Burden and health outcomes of family caregivers of hospitalized bone marrow transplant patients. J Adv Nurs 1996;24:915-23.

18. Bishop MM, Beaumont JL, Hahn EA, et al. Late effects of cancer and hematopoietic stem-cell transplantation on spouses or partners compared with survivors and survivor-matched controls. J Clin Oncol 2007;25:1403-11.

19. Min SK, Kim KI, Lee CI, Jung YC, Suh SY, Kim DK. Development of the Korean versions of WHO Quality of Life scale and WHOQOL-BREF. Qual Life Res 2002;11:593-600.

20. Development of the World Health Organization WHOQOLBREF quality of life assessment. The WHOQOL Group. Psychol Med 1998;28:551-8.

21. Chen L, Luo LF, Lu J, et al. FTY720 induces apoptosis of M2 subtype acute myeloid leukemia cells by targeting sphingolipid metabolism and increasing endogenous ceramide levels. PLoS One 2014;9:e103033.

22. Han C, Jo SA, Kwak JH, et al. Validation of the Patient Health Questionnaire-9 Korean version in the elderly population: the Ansan geriatric study. Compr Psychiatry 2008;49:218-23.

23. Spitzer RL, Kroenke K, Williams JB. Validation and utility of a self-report version of PRIME-MD: the PHQ primary care study. Primary care evaluation of mental disorders. Patient Health Questionnaire. JAMA 1999;282:1737-44.

24. Spitzer RL, Williams JB, Kroenke K, Hornyak R, McMurray J. Validity and utility of the PRIME-MD Patient Health Questionnaire in assessment of 3000 obstetric-gynecologic patients: the PRIME-MD Patient Health Questionnaire ObstetricsGynecology Study. Am J Obstet Gynecol 2000;183:759-69.

25. Kroenke K, Spitzer RL, Williams JB. The PHQ-9: validity of a brief depression severity measure. J Gen Intern Med 2001;16:606-13.

26. Lude P, Kennedy P, Elfstrom ML, Ballert CS. Quality of life in and after spinal cord injury rehabilitation: a longitudinal multicenter study. Top Spinal Cord Inj Rehabil 2014;20:197-207.

27. Mohan A, Mohan C, Pathak AK, Pandey RM, Guleria R. Impact of chronic obstructive pulmonary disease on respiratory status and quality of life in newly diagnosed patients with lung cancer. Respirology 2007;12:240-7.

28. Hancock P, Larner AJ. Clinical utility of Patient Health Questionnaire-9 (PHQ-9) in memory clinics. Int J Psychiatry Clin Pract 2009;13:188-91.

29. Hinz A, Mehnert A, Kocalevent RD, et al. Assessment of depression severity with the PHQ-9 in cancer patients and in the general population. BMC Psychiatry 2016;16:22.

30. Wulff-Burchfield EM, Jagasia M, Savani BN. Long-term follow-up of informal caregivers after allo-SCT: a systematic review. Bone Marrow Transplant 2013;48:469-73.

31. Bishop MM. Psychosocial sequelae of hematopoietic cell transplantation in survivors and caregivers. Biol Blood Marrow Transplant 2009;15:29-32.

32. Meehan KR, Fitzmaurice T, Root L, Kimtis E, Patchett L, Hill J. The financial requirements and time commitments of caregivers for autologous stem cell transplant recipients. J Support Oncol 2006;4:187-90.

33. Noerholm V, Groenvold M, Watt T, Bjorner JB, Rasmussen NA, Bech P. Quality of life in the Danish general population-normative data and validity of WHOQOL-BREF using Rasch and item response theory models. Qual Life Res 2004;13:531-40.

34. Hanestad BR, Rustøen T, Knudsen O Jr, Lerdal A, Wahl AK. Psychometric properties of the WHOQOL-BREF questionnaire for the Norwegian general population. J Nurs Meas 2004;12: 147-59. 